\title{
Anisotropy Control of a High-Frequency Carrier-Type Magnetic Field Sensor by Shape Anisotropy
}

\author{
T. Kato, K. Ishiyama, and K. I. Arai \\ Research Institute of Electrical Communication, Tohoku Univ., Katahira 2-1-1, Aoba-ku, Sendai 980-8577, Japan
}

We tried to control the magnetic anisotropy of a high-frequency carrier-type magnetic field sensor by varying the shape of the magnetic film instead of the induced anisotropy. We confirmed that the impedance of the sensor was changed by applying a magnetic field, and showed that the properties of the sensor could be controlled through the design of the magnetic film's shape.

Key words: high-frequency carrier-type magnetic field sensor, shape anisotropy, anisotropy control, thin film

\section{形状磁気異方性による高周波キャリア型磁界センサの異方性制御 \\ 加藤 智紀, 石山 和志, 荒井 賢一 \\ 東北大学電気通信研究所, 仙台市青葉区片平 2-1-1（干980-8577）}

\section{1. はじめに}

高透磁率磁性体一高周波電流やパルス波を直接通電し，外部磁 界を印加することで，その透磁率変化を介し，表皮効果及び自然 共鳴によりインピーダンスが大きく変化することを利用した磁界 センサは, MI センサあるいは高周波キャリア型磁界センサと呼ば れ, 高感度化の研究及び産業応用が議論されている 1)2). このセン サ素子の磁界検出の感度限界は熱による磁化のゆらぎで決定され, その值は室温で $10^{-13} \mathrm{~T}$ 台に達するとの報告がある 3 ， この磁界セ ンサの高感度化においては, 磁性薄膜の一軸磁気異方性を制御す ることが重要となる.

これまでに, 磁界中熱処理によってアモルファス $\mathrm{CoNbZr}$ 薄膜 に誘導磁気異方性を付与した高周波キャリア型磁界センサが報告 されている4).このセンサ素子は熱処理温度により磁性薄膜の異方 性強度を制御し高感度化を図ったものであった。一方，磁性薄膜 の異方性分散を低減させると, インピーダンス変化が急峻になり 更なる高感度化が望めると考えられる。 しかし磁界中熱処理によ る異方性制御のみでは, 磁性薄膜の異方性強度と異方性分散を共 に制御することは困難であった。

本研究は磁界中熱処理に代わる新たな異方性制御を試みること により高周波キャリア型磁界センサの更なる高感度化を目指寸も のである. 本報告では新たな異方性制御の一つとして形状磁気異 方性に注目し，磁性薄膜の反磁界を制御することによりセンサ特 性の制御を試みた結果について述べる，具体的には，形状磁気異 方性を利用したセンサを提案し，素子の異方性強度を小さくする ことを目的とした素子設計を行った. さらに設計に基づいて試作 したセンサのインピーダンスを測定し，センサ特性を評価した。

\section{2. 形状磁気異方性を利用したセンサ}

\section{1 センサ構造}

Fig. 1 に従来のセンサ素子と本研究で提案するセンサ素子の概 念図を示す．従来のセンサ素子は磁性薄膜に磁界中熱処理を施す ことにより，磁化容易軸を素子幅方向とした誘導磁気異方性を付 与していた. これに対して提案するセンサ素子は磁性薄膜を磁化 容易軸を長辺とする短冊状に加工し，素子に形状磁気異方性を付
与した. これにより磁性膜は通電方向に対して分断されるため, 導電体を形成しここにキャリア電流を通電する構造とした. この ように磁性薄膜を短冊状に加工し導電体にキャリア電流を通電す る構造は，千田氏らによる先行研究 5) 6) と類似した構造となって いる. 先行研究では外部磁界入射方向の膜面内反磁界を抑えるた め磁性薄膜を短冊状に加工しているのに対して, 本研究では素子 の異方性を磁性薄膜の形状により制御する事を目的とし Fig. 1(b) に示すようなセンサ構造とした.

このようなセンサ構造にすることにより磁性薄膜の寸法比によ りセンサ素子の異方性強度の制御が可能となる. また, 素子の異 方性は磁性薄膜の形状でのみ決まるので, 磁性薄膜の形状を精度 よく加工することにより異方性分散の低減化も期待される.

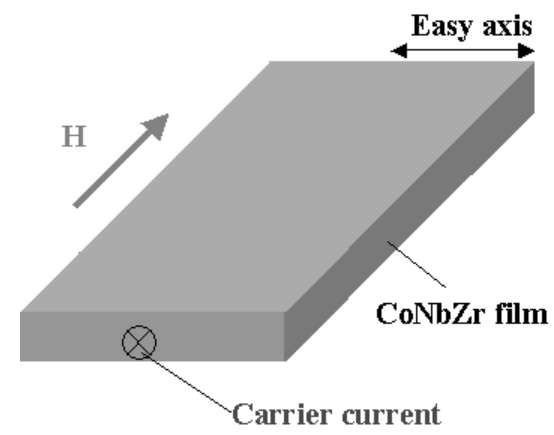

(a) Induced anisotropy

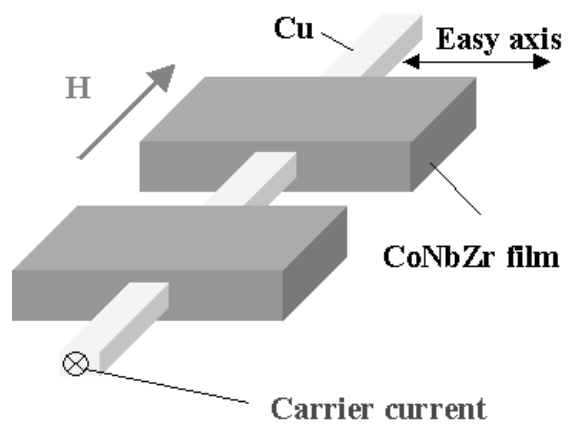

(b) Shape anisotropy

Fig. 1 Conceptual diagram of sensor elements. 


\section{2 素子設計}

本センサは理論的には素子の異方性強度と等しい磁界強度を印 加した時にインピーダンスが最大となる. これは，外部磁界によ って磁性薄膜の磁化が回転し, 磁化が全て困難軸方向を向いた時 に透磁率が最大となるためである.インピーダンスが最大值とな る外部磁界を小さくすることによりインピーダンスはより急峻に 変化するため, センサの高感度化においては磁性薄膜の異方性強 度を小さくする必要がある. 本センサ素子では磁性薄膜の磁気特 性が等方性であると仮定すると, 磁化が困難軸方向に飽和する時 の磁界強度と磁性膜幅方向の反磁界強度は等しくなる. そこで磁 性膜幅方向の反磁界強度を素子の異方性強度と仮定して素子設計 を行った. (1)式に磁性膜幅方向の反磁界強度 $H_{\mathrm{d}}$ の計算式を示す.

$$
H_{d}=N \frac{M_{s}}{\mu_{0}}
$$

$M \mathrm{~s}$ は磁生薄膜の飽和磁化量を表しており, 本研究では磁生体と してアモルファス $\mathrm{CoNbZr}$ を用いたので $1 \mathrm{~T}$ とた。 また， $N$ は 反磁界係数を表しており，回転楕円体近似によって計算すること が出来る ${ }^{7)}$. 磁性膜幅方向の反磁界係数を求める計算式を式(2)お よび式(3)に示す.

$a \geq b>>c$ の時

$$
\begin{aligned}
& N=\frac{c}{a} \frac{E-\left(1-e^{2}\right) K}{e^{2}\left(1-e^{2}\right)^{\frac{1}{2}}} . \\
& e=\left(1-b^{2} / a^{2}\right)^{\frac{1}{2}} .
\end{aligned}
$$

ここで $a$ は磁性薄膜の長さ， $b$ は幅， $c$ は膜厚を表しており， $K$ は $e$ を引数とした第 1 種完全楕円積分, 同様に $E$ は第 2 種完全 楕円積分である.

式(1)〜式(3)を用いて従来のセンサの異方性磁界強度と同じ值で ある $7 \mathrm{Oe}(0.6 \mathrm{kA} / \mathrm{m})$ を指標として, 磁生薄膜の短冊の寸法を計算 した. 従来のセンサと同程度のセンササイズにするには磁性薄膜 の長さを $100 \mu \mathrm{m}$ 以下にする必要があるが，この場合磁性薄膜の 膜厚を数 $10 \mathrm{~nm}$ にする必要がある. しかし，膜厚を非常に薄くす ると磁気特性が劣化してしまう恐れがあるため, 本研究では磁性 薄膜の膜厚を最低 $0.5 \mu \mathrm{m}$ と設定した. この場合反磁界も大きくな るため磁性薄膜を大きくする必要がある. そこで今回は磁性膜の 長さを $1 \mathrm{~mm}$ とした. このとき磁生膜の幅を $400 \mu \mathrm{m}$ とすれば反 磁界強度は $11 \mathrm{Oe}(0.9 \mathrm{kA} / \mathrm{m})$ となり従来のセンサに近い值となる.

\section{3. センサ素子}

\section{1 素子作製}

Fig. 2 に作製したセンサの模式図を示す. 本研究では磁性体とし て $\mathrm{Co}_{85} \mathrm{Nb}_{12} \mathrm{Zr}_{3}$ を用い，高周波キャリアを通電する導電体として $\mathrm{Cu}$ を用いた. 前述のように磁牲膜のサイズが決定されたことから

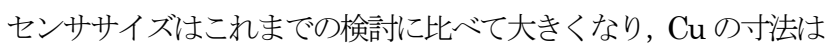
長さ $15 \mathrm{~mm}$, 幅 $100 \mu \mathrm{m}$, 膜厚 $0.5 \mu \mathrm{m}$ となった. CoNbZr の寸法 は長さ $1 \mathrm{~mm}$, 幅 $W$ を $100 \mu \mathrm{m}, 200 \mu \mathrm{m}, 400 \mu \mathrm{m}$, 膜厚 $0.5 \mu \mathrm{m}$ とした. また隣接する磁性薄膜が互いに影響を及ぼさないように
するために, 磁生薄膜の間隔を $4 W$ とした. このように磁性薄膜の 幅 $W$ を可変とすることで, 磁性薄膜の形状を変化させてセンサ素 子の異方性強度を制御した.

Fig. 3 にセンサの作製工程を示寸. 作製手順は以下の通りである.

1. レジストを 1 インチのガラス基板上に厚さ約 $2 \mu \mathrm{m}$ 塗布しフ オトリソグラフィー技術によりレジストパターニングを行う.

2. RF スパッタ法により $\mathrm{CoNbZr}$ 薄膜を成膜する. $\mathrm{CoNbZr}$ 薄 膜の成膜条件は 投入電力 $200 \mathrm{~W}, \mathrm{Ar}$ ガス圧 20 mTorr とし た. また成膜時に磁界は印加せず, 成膜後の熱処理も施さな かった.

3. 有機溶剤によりレジストおよびレジスト上に成膜された磁生 膜を同時に剥離し(リフトオフ), パターニングを行う。

4. $1 \sim 3$ の手順を繰り返し $\mathrm{Cu}$ 薄膜, $\mathrm{CoNbZr}$ 薄膜(2 層目)の順 にパターニングを行いセンサを作製した.

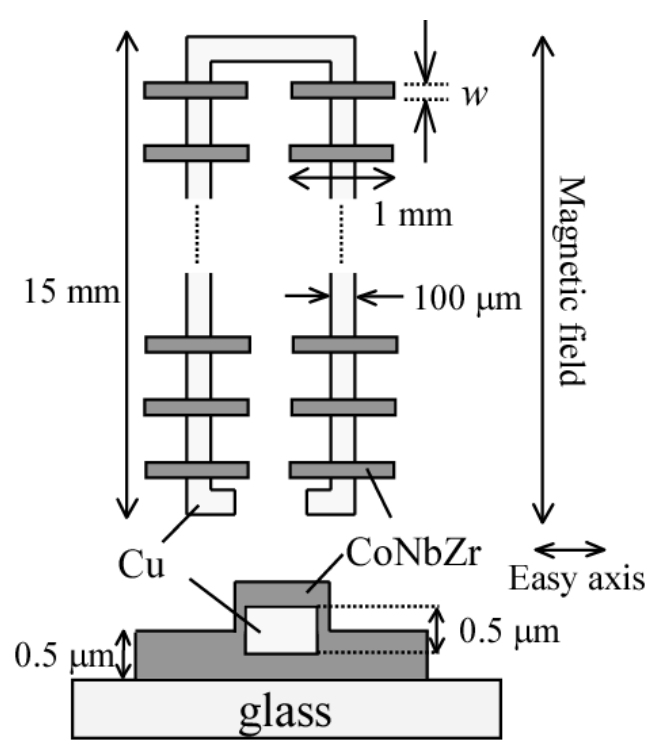

Fig. 2 Schematic view of sensor elements.

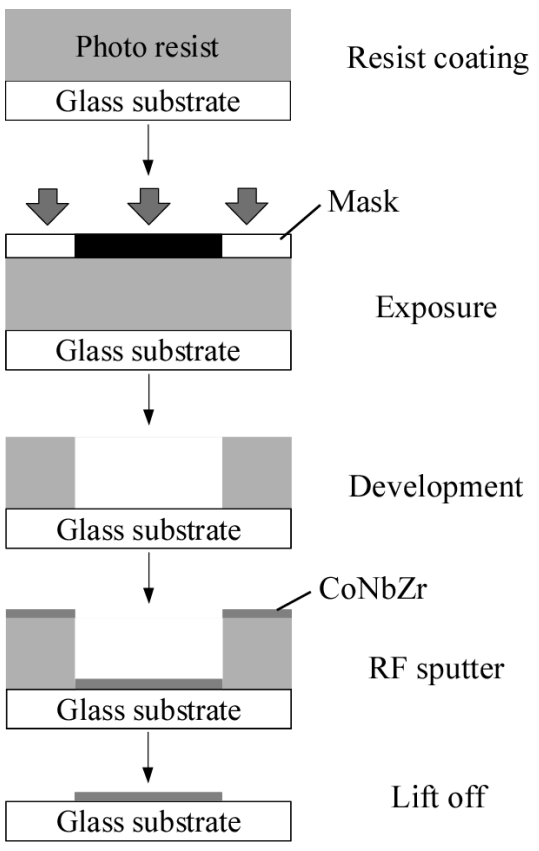

Fig. 3 Process chart. 


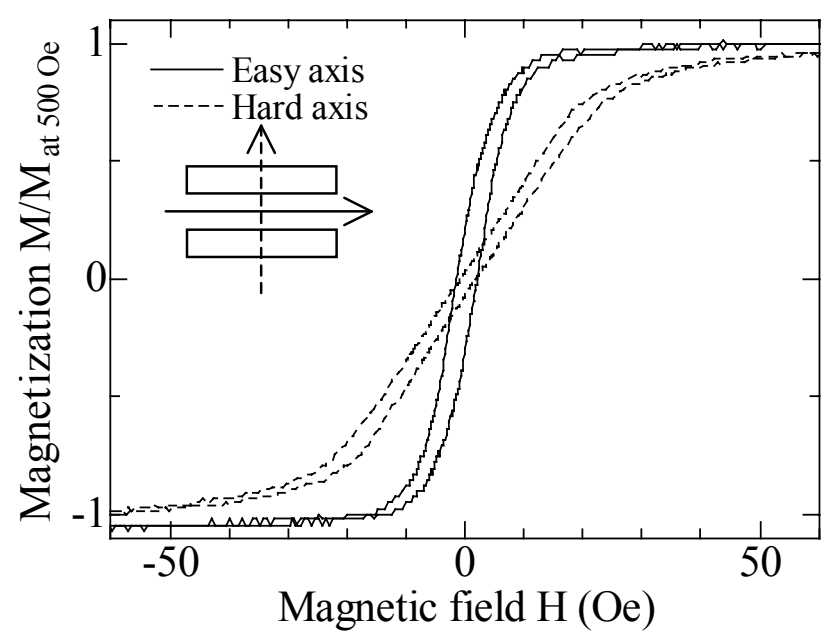

Fig. 4 M-H loops of the sensor.

\section{2 磁気特性}

Fig. 4 に作製したセンサ素子の磁化曲線を示す. 測定した素子は 磁性薄膜の幅が $200 \mu \mathrm{m}$ の素子であり, 振動試料型磁力計(VSM) を用いて測定した. Fig. 4 において実線は磁生膜長さ方向の磁化曲 線であり, 破線は磁性膜幅方向の磁化曲線である. 測定結果から 磁性膜長さ方向を磁化容易軸とする一軸磁気異方性が付与されて いることが分かる．この結果から形状磁気異方性によって素子に 一軸磁気異方性が付与されていることを確認した。

式(1)を用いて測定した長さ $1 \mathrm{~mm}$, 幅 $200 \mu \mathrm{m}$, 膜厚 $0.5 \mu \mathrm{m}$ で ある磁性膜の幅方向の反磁界強度を計算した. その結果 $24 \mathrm{Oe}$ $(1.9 \mathrm{kA} / \mathrm{m})$ という計算值を得た. Fig. 4 から磁生膜幅方向では磁化 が飽和し始める磁界強度と反磁界強度の計算值は概ね一致してい る事がわかる. この結果から, 反磁界強度の計算の妥当性が示さ れた.

\section{4. 実験}

\section{1 実験方法}

センサ素子の外部直流磁界対インピーダンスの関係を測定した Fig. 5 はセンサ素子のインピーダンス測定系を示したものである. インピーダンスはネットワークアナライザを用いて反射法 ${ }^{8)} に よ$ り測定した. 外部直流磁界はヘルムホルツコイルによりセンサ素 子の磁化困難軸方向に印加した. ネットワークアナライザからセ ンサ素子への入力電力は一 $10 \mathrm{dBm}$ で一定とし, 磁化容易軸方向に 微小振幅の交流励磁が行われるように高周波キャリアを通電した.

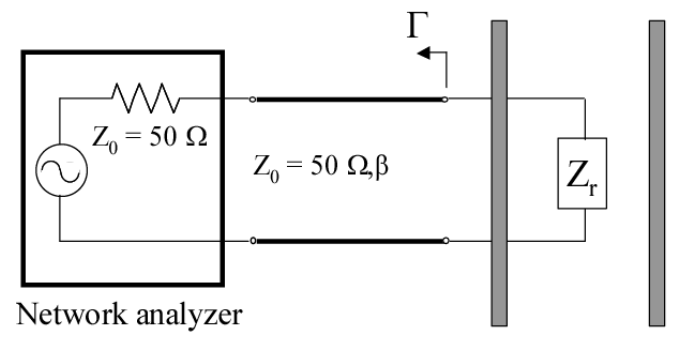

Helmholtz coil

Fig. 5 Impedance measurement system.

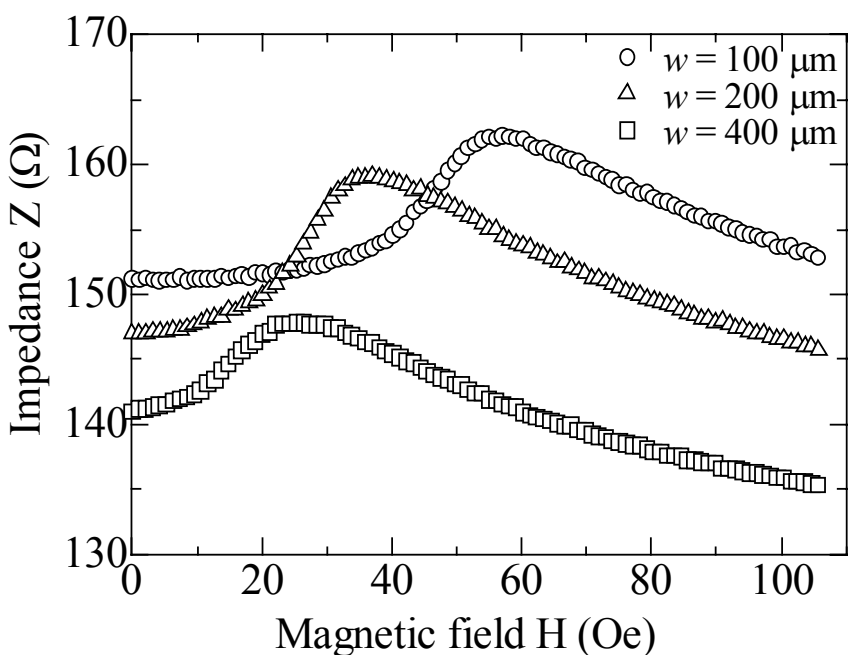

Fig. 6 Relationship between the magnetic field and the impedance of the sensor.

Table 1 Relationship between $H_{d c}$ at maximum impedance and the demagnetizing field.

\begin{tabular}{|r|r|r|}
\hline \multicolumn{1}{|c|}{$\begin{array}{c}\text { Width of the } \\
\text { magnetic film }(\mu \mathrm{m})\end{array}$} & $\begin{array}{c}\text { Hat maximum } \\
\text { impedance }(\mathrm{Oe})\end{array}$ & $\begin{array}{c}\text { Demagnetizing } \\
\text { field }(\mathrm{Oe})\end{array}$ \\
\hline 100 & 55 & 49 \\
\hline 200 & 37 & 24 \\
\hline 400 & 26 & 11 \\
\hline
\end{tabular}

\section{2 実験結果}

外部直流磁界 $H$ に対するセンサ素子のインピーダンス変化の測 定結果を Fig. 6 に示す. 丸プロットは磁性薄膜の幅 $100 \mu \mathrm{m}$ の結 果, 三角プロットは幅 $200 \mu \mathrm{m}$ の結果, 四角プロットは幅 $400 \mu \mathrm{m}$ の結果である. キャリア周波数は $550 \mathrm{MHz}$ であり，このとき全て のセンサ素子でインピーダンスの変化量が最大となった.

磁生薄膜の幅 $100 \mu \mathrm{m}$ のセンサ素子のインピーダンスは, 外部 磁界 0 の時に $151 \Omega$ ズったが磁界の増加とともに上昇し, 外部 磁界 $55 \mathrm{Oe}(4.3 \mathrm{kA} / \mathrm{m})$ で最大值 $162 \Omega$ をとり, その後減少した. 他 の 2 つのセンサ素子に関しても同様な傾向を示し, 幅 $200 \mu \mathrm{m}$ の

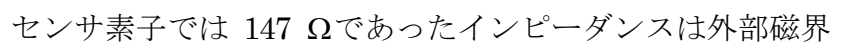
$37 \mathrm{Oe}(2.9 \mathrm{kA} / \mathrm{m})$ )時最大值 $159 \Omega$ となり, 幅 $400 \mu \mathrm{m}$ のセンサ素 子では $141 \Omega$ あったインピーダンスは外部磁界 $26 \mathrm{Oe}$ $(2.1 \mathrm{kA} / \mathrm{m})$ の時最大值 $148 \Omega$ となった. この実験結果から形状磁気 異方性を利用したセンサ素子で磁気一インピーダンス効果が生じ ることを示した. また, 磁性膜の幅によってインピーダンスピー ク時の外部磁界強度が変化していることを確認した。

Table 1 にインピーダンスが最大值となる外部磁界強度と磁性 膜幅方向の反磁界強度の計算值を示寸. Table 1 からインピーダン スが最大值となる外部磁界強度と幅方向の反磁界強度は概ね一致 していることが分かる. この結果から磁性薄膜の形状によって異 方性強度の制御が可能であることを示した。

これらの結果から, 形状磁気異方性を利用したセンサが高周波 キャリア型磁界センサ素子として実現可能であることを示した. 


\section{5. 今後の課題}

本報告で作製したセンサ素子はまだ反磁界が大きく，センササ イズを小さくするとさらに反磁界が大きくなる．そのため磁性膜 の形状による異方性制御に加え，新たな異方性制御を導入する必 要がある. そこで我々は磁性薄膜の閒隔を減少させることにより 磁化困難軸方向の反磁界を緩和寸ることを考えている. 磁性薄膜 の間隔を狭くすると, 磁性薄膜が密になり連接する磁性薄膜の静 磁結合によりマクロ的には 1 つ短冊状の磁生薄膜とみなすこと が出来る ${ }^{9)}$.これを利用した磁性薄膜の間隔による新たな異方性制 御の検討を開始している.

\section{6. まとめ}

反磁界強度を求めることによりセンサ素子設計の指針とした. 指針に基づきセンサ素子を製作し，磁気一インピーダンス効果が 生じることを確認した．また，磁性薄膜の形状によって異方性強 度を制御出来ることを示し，これらの検討により形状磁気異方性 を利用したセンサが高周波キャリア型磁界センサとして実現可能 であることを示した.

\section{References}

1) A. Takayama, T. Umehara, A. Yuguchi, H. Kato, K. Mohri, T. Uchiyama : J. Magn. Soc. Jpn., 24, 763 (2000).

2) S. Yabukami, T. Suzuki, N. Ajiro, H. Kikuchi, M. Yamaguchi, and K. I. Arai : IEEE Trans. Magn., 37, 2019 (2001).

3) M. Takezawa : Doctoral dissertation of Tohoku University, p. 216 (1999).

4) Y. Murayama, T. Ozawa, N. Horikoshi, S. Yabukami, K. Ishiyama, and K. I. Arai : J. Magn. Soc. Jpn., 30, 237 (2006).

5) M. Senda, O. Ishii, Y. Koshimoto and T. Toshima : IEEE Trans. Magn., 30, 4611 (1994).

6) M. Senda, H. Takei, O. Ishii, Y. Koshimoto and T. Toshima : J. Magn. Soc. Jpn., 19, 465 (1995).

7) J. A. Osborn : Physical Review, 67, 351(1945).

8) K. I. Arai, M. Yamaguchi, and H. Ohzeki : IEEE Trans, Magn., 28, 2175(1992).

9) M. Masuda, S. Shiomi and M. Shiraki : J. Appl. Jpn., 26, 1680(1987)

2006年10月5日受理，2007年3月19日採録 